\title{
Implementasi Sistem Keamanan WPA2-PSK pada Jaringan WiFi
}

\author{
Baihaqi $1^{*}$, Yeni Yanti ${ }^{2}$, Zulfan $^{3}$ \\ 1,2,3 Staf Pengajar Program Studi Teknik Informatika \\ Fakultas Teknik Universitas Serambi Mekkah \\ Jl. T. Imum Lueng Bata Batoh - Banda ceh \\ *Koresponden email: b_baihaqi@yahoo.co.id
}

Diterima: 13 Desember 2017

Disetujui: 18 Desember 2017

\begin{abstract}
Nowadays the use of WiFi network technology device has been widely developed around the world, both used for voice and data communications. WiFi networks utilize high frequencies to deliver and connect a communication, then the vulnerability to security is also higher than with other communication technologies. Various security measures can be done through communication devices used by users or by operators who provide communication services. However, with the user who utilizes WiFi network technology, it can provide little security hole that can be exploited by the attacker. Then the attacker can find out the WPA2-PSK security password when the user connects to the WiFi network. So the resulting password through several techniques and testing used. Among them by utilizing the user connected to the WiFi network, testing fake SSID and testing WPS PIN. However, in this study only conducted testing through a user connected to a WiFi network. This technique and testing is solely done to penetrate the security of WiFi network, which aims to know the password of WPA2-PSK on WiFi network and to add insight about WiFi network security.
\end{abstract}

Keywords: Password, WPA2-PSK, User, WiFi

Abstrak. Dewasa ini penggunaan perangkat teknologi jaringan WiFi sudah berkembang luas di seluruh dunia, baik digunakan untuk komunikasi suara maupun data. Jaringan WiFi memanfaatkan frekuensi tinggi untuk menghantarkan dan menghubungkan sebuah komunikasi, maka kerentanan terhadap keamanan juga lebih tinggi dibanding dengan teknologi komunikasi yang lainnya. Berbagai tindakan pengamanan dapat dilakukan melalui perangkat komunikasi yang digunakan oleh user maupun oleh operator yang memberikan layanan komunikasi. Namun, dengan adanya user yang memanfaatkan teknologi jaringan WiFi, maka dapat memberikan sedikit celah keamanan yang dapat dimanfaatkan oleh penyerang. Kemudian penyerang dapat mengetahui password keamanan WPA2-PSK pada saat user terhubung ke jaringan WiFi tersebut. Sehingga dihasilkan password melalui beberapa teknik dan pengujian yang digunakan. Diantaranya dengan memanfaatkan user yang terhubung ke jaringan WiFi, pengujian SSID palsu dan pengujian WPS PIN. Namun pada penelitian ini hanya dilakukan pengujian melalui user yang terhubung ke jaringan WiFi. Teknik dan pengujian ini semata-mata dilakukan untuk penetrasi terhadap keamanan jaringan WiFi, yang bertujuan untuk mengetahui password WPA2-PSK pada jaringan WiFi serta untuk menambah wawasan tentang keamanan jaringan WiFi.

Kata Kunci : Password, WPA2-PSK, User, WiFi

\section{Pendahuluan}

Teknologijaringan wireless saatiniberkembang sangat pesat terutama dengan hadirnya perangkat teknologi informasi dan komunikasi. Komputer, notebook, PDA, telepon seluler (handphone) dan periferal lainnya mendominasi pemakaian teknologi jaringan wireless. Penggunaan teknologi jaringan wireless yang di implementasikan dalam suatu jaringan lokal sering dinamakan WLAN (Wireless Local Area Network). Teknologi jaringan wireless memanfaatkan frekuensi tinggi untuk menghantarkan sebuah komunikasi, maka 


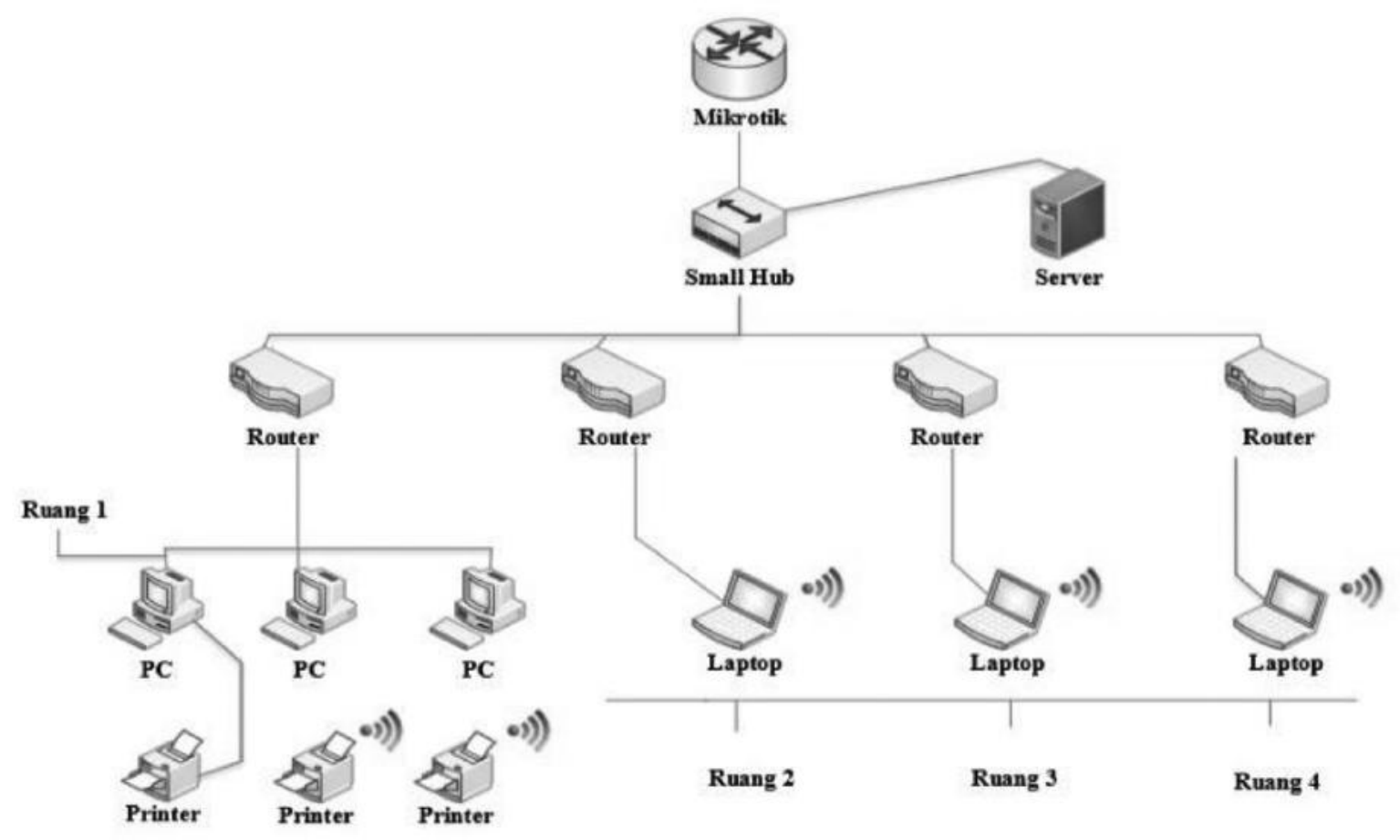

Gambar 1. Sistem jaringan WLAN

kerentanan terhadap keamanan juga lebih tinggi dibanding dengan teknologi komunikasi yang lainnya. Berbagai tindakan pengamanan dapat dilakukan melalui perangkat komunikasi yang di gunakan oleh user maupun oleh operator yang memberikan layanan komunikasi. Namun dengan adanya user yang memanfaatkan teknologi jaringan WiFi, maka dapat memberikan sedikit celah keamanan kepada penyerang, sehingga penyerang dapat mengetahui password keamanan WPA2-PSK pada saat user terhubung ke jaringan WiFi. Kelemahan jaringan wireless secara umum dapat dibagi menjadi dua jenis, yakni kelemahan pada konfigurasi dan kelemahan pada jenis enkripsi yang digunakan. Secara garis besar, celah pada jaringan wireless terbentang di atas empat layer di mana keempat lapis layer tersebut sebenarnya merupakan proses terjadinya komunikasi data pada media wireless. Keempat lapis tersebut adalah lapis fisik, lapis jaringan, lapis user, dan lapis aplikasi.

Keamanan sistem jaringan wireless menjadi suatu keharusan untuk lebih diperhatikan, karena jaringan internet yang sifatnya publik dan global pada dasarnya tidak aman. Adanya lubang-lubang keamanan pada sistem jaringan menyebabkan kelemahan dan terbukanya lubang yang dapat digunakan para hacker, cracker dan script kiddies untuk memanfaatkan pengaksesan jaringan secara bebas, pembobolan password keamanan pada jaringan wireless, dan lain-lain. Oleh karena itu, penulis ingin mengimplementasikan sistem keamanan WPA2-PSK pada jaringan WiFi untuk mengetahui password WPA2-PSK melalui user yang terhubung ke jaringan WiFi.

\section{Tinjauan Pustaka}

Menurut Sinambela dan Josua (2007) Group 802.11i akhirnya menyelesaikan metode keamanan yang awalnya ditugaskan dari IEEE. Level keamanan ini kemudian dinamakan sebagai WPA2. WPA2 merupakan level keamanan yang paling tinggi. Enkripsi utama yang digunakan pada WPA2 ini yaitu enkripsi AES. AES mempunyai kerumitan yang lebih tinggi daripada RC4 pada WEP sehingga para vendor tidak sekedar upgrade firmware seperti dari WEP ke WPA. Untuk menggunakan WPA2 diperlukan hardware baru yang mampu bekerja dengan lebih cepat dan mendukung perhitungan yang dilakukan oleh WPA2. Sehingga tidak semua adapter mendukung level keamanan WPA2 ini.

Pada security mode WPA2-PSK ada dua pilihan enkripsi pada jenis ini, yaitu TKIP dan 


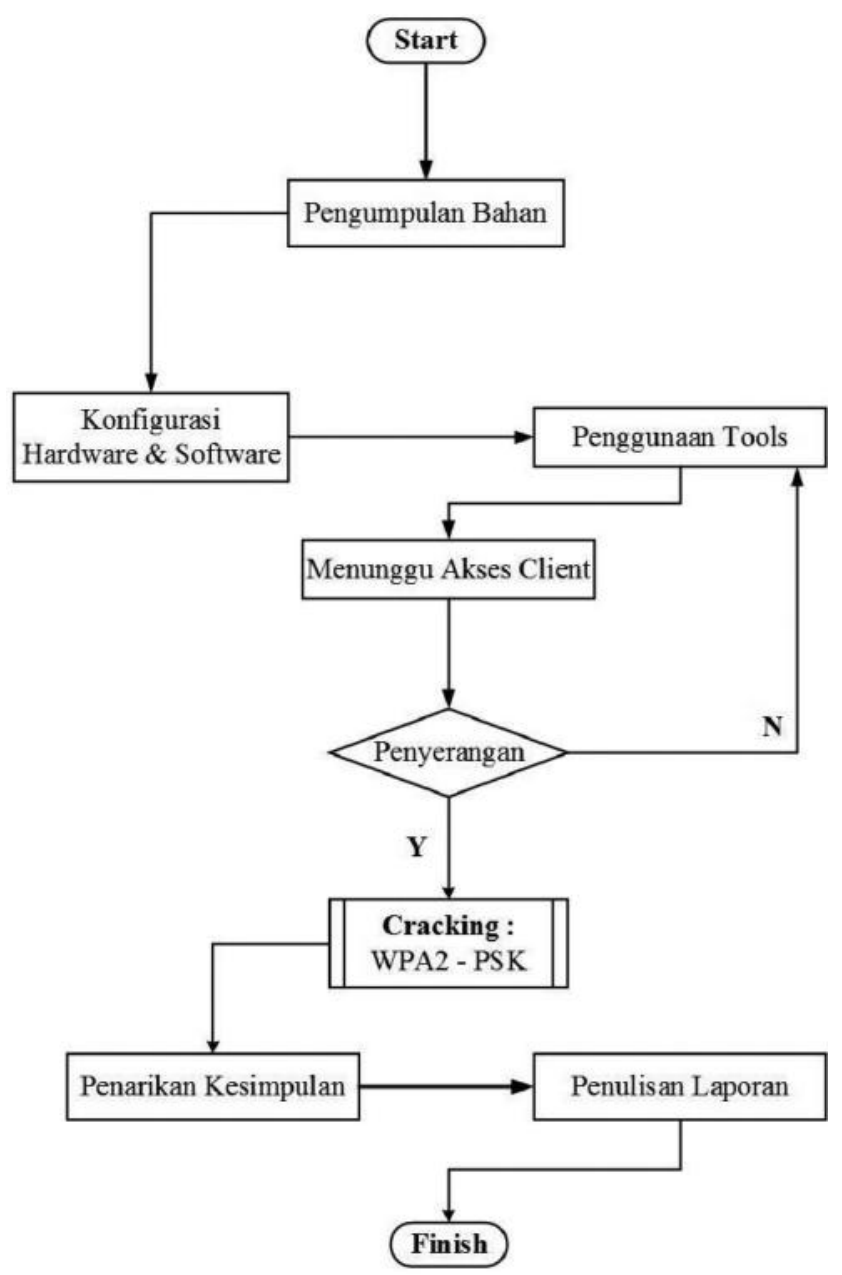

Gambar 2. Flowchart IDS (Intrusion Detection System)

AES. TKIP (Temporal Key Integrity Protocol) menggunakan metode enkripsi yang lebih aman dan juga menggunakan MIC (Message Integrity Code) untuk melindungi jaringan dari serangan. Sedangkan AES (Advanced Encryption System) menggunakan enkripsi 128 bit blok data secara simetris. Untuk menggunakan WPA Pre-Shared Key, masukkan password pada WPA Shared Key dengan panjang karakter antara 8 sampai 63. Group Key Renewal Interval diisi dengan nilai default yaitu 3600 seconds.

Menurut Priyambodo dan Tri Kuntoro (2008) WiFi atau Wireless Fidelity adalah satu standar Wireless Networking tanpa kabel, hanya dengan komponen yang sesuai dapat terkoneksi ke jaringan.

Menurut Supriyanto dan Aji (2007) kelemahan jaringan WiFi secara umum dapat dibagi menjadi 2 jenis, yakni kelemahan pada konfigurasi dan kelemahan pada jenis enkripsi yang digunakan. Salah satu contoh penyebab kelemahan pada

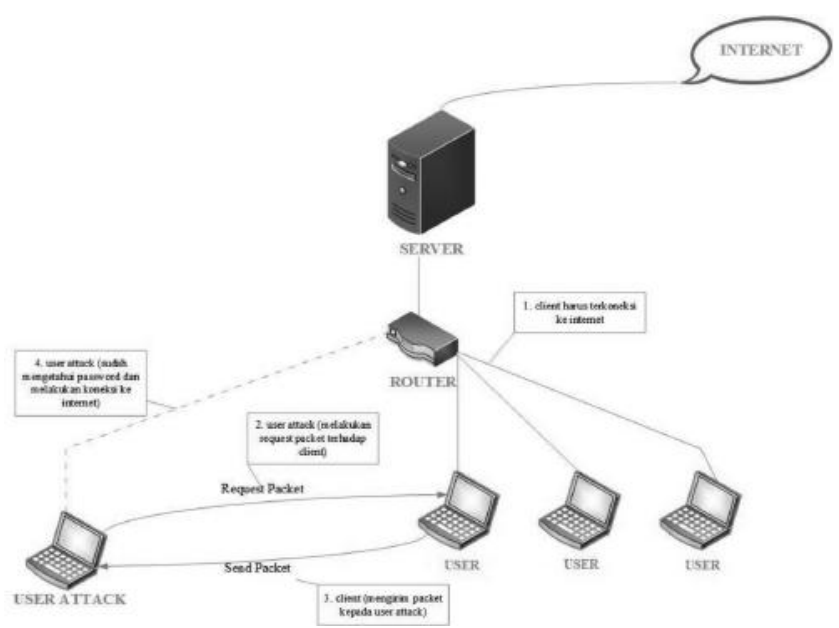

Gambar 3. Topologi tree jaringan WLAN pada tahapan mengetahui password

konfigurasi karena saat ini untuk membangun sebuah jaringan WiFi cukup mudah. Banyak vendor yang menyediakan fasilitas yang memudahkan pengguna atau admin jaringan sehingga sering ditemukan wireless yang masih menggunakan konfigurasi wireless default bawaan vendor yang dapat diserang oleh hacker melalui IP spoofing. Menurut Prabowo (2010) hacker adalah sebutan untuk mereka yang memberikan sumbangan bermanfaat untuk dunia jaringan dan sistem operasi. Membuat teknologi internet semakin maju karena hacker menggunakan keahliannya dalam hal komputer untuk melihat, menemukan dan memperbaiki kelemahan sistem keamanan dalam sebuah sistem komputer.

Menurut Suryani dan Izny (2013) password attack adalah istilah umum yang menggambarkan sekelompok teknik yang digunakan untuk memperoleh password pada sebuah sistem data. Password attack khusus mengacu pada proses mendapatkan password dari data yang yang dilindungi dengan password, namun harus dicatat bahwa cara-cara menipu seseorang agar memberi password, seperti melalui phishing, tidak dianggap sebagai password attack. Menurut Satria dan Lucky (2014) IP spoofing dapat didefinisikan sebagai teknik yang digunakan untuk memperoleh akses yang tidak sah ke suatu komputer atau informasi, dimana penyerang berhubungan dengan pengguna dengan berpurapura memalsukan bahwa mereka adalah host yang dapat dipercaya. Beberapa kerentanan dan 


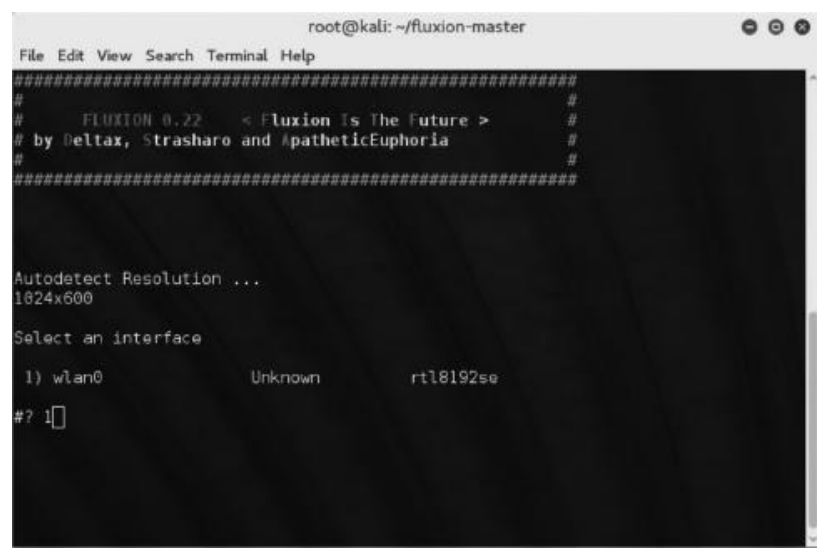

Gambar 4. Tampilan tool Fluxion

serangan yang sangat umum terdapat di dalam sebuah jaringan wireless, diantaranya (Heather, 2009):

1. Tidak ada konfigurasi atau Poor Security

2. Tidak ada pengaturan batas

3. Lokasi yang tidak aman

4. Pengguna tidak mengatur jaringan dengan baik

5. Adanya Rogue Acces Point

6. Kelemahan dalam memantau jaringan

7. MAC filtering

8. Standar enkripsi yang tidak memadai

9. War driving

10. Serangan Man in The Middle

11. Serangan Denial of Service

Enkripsi adalah proses penggunaan algoritma yang kompleks untuk mengkonversi pesan (plaintext) ke suatu pesan terenkripsi (chipertext). Hal ini ditujukan untuk mengamankan suatu informasi dengan membuat informasi tersebut tidak dapat dibaca tanpa bantuan pengetahuan khusus (Wirdasari dan Dian, 2008).

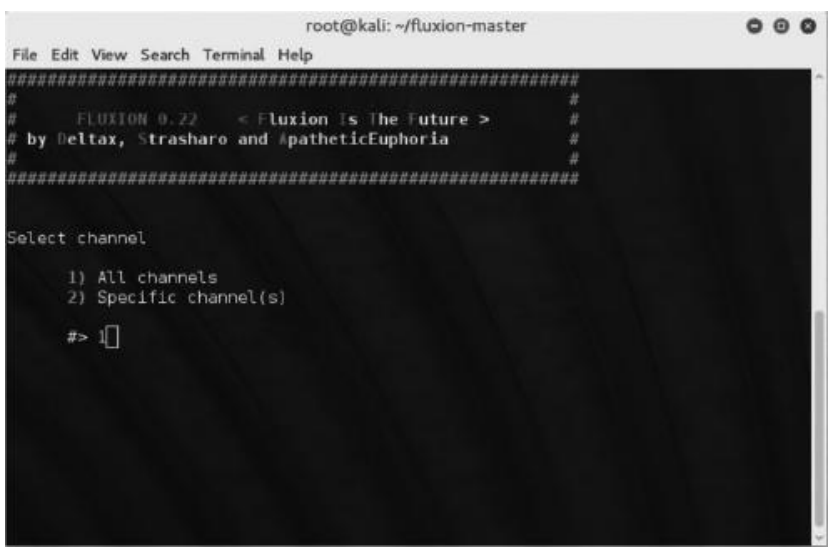

Gambar 5. Pemilihan Channel jaringan WiFi

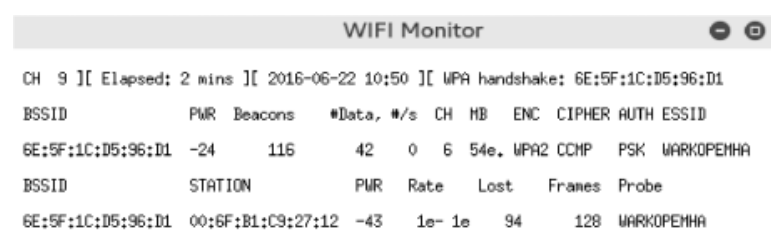

Gambar 6. Informasi mengenai jaringan WiFi dan user

\section{Metodelogi Penelitian}

Penelitian ini dimulai dengan mengamati topologi jaringan yaitu topologi tree seperti terlihat pada Gambar 1. Topologi jaringan akan dianalisa untuk mengetahui password WPA2PSK melalui user yang terhubung ke jaringan tersebut. Pada topologi jaringan WLAN tersebut dapat dideskripsikan bahwa sebuah small hub atau switch yang terhubung ke server sebagai media gateway dari router ke server dan internet untuk melakukan akses ke jaringan internet, sedangkan router sebagai media penghubung antara client dengan switch melalui sebuah access point yang telah di konfigurasikan di dalam router tersebut, serta berfungsi juga sebagai penentuan alamat IP address suatu komputer client dengan IP address 192.168.1.1 - 192.168.1.254.

Dari Flowchart IDS yang terlihat pada gambar 2 dapat dijelaskan beberapa tahapan - tahapan sebagai berikut:

1. Pengumpulan bahan, mencari tutorial tutorial baik dari internet, buku dan artikel - artikel tentang masalah yang berhubungan dengan keamanan jaringan wireless.

2. Menyiapkan hardware dan software yang dibutuhkan seperti menggunakan terminal Kali Linux dan tool-tool tambahan lainnya untuk proses penyerangan.

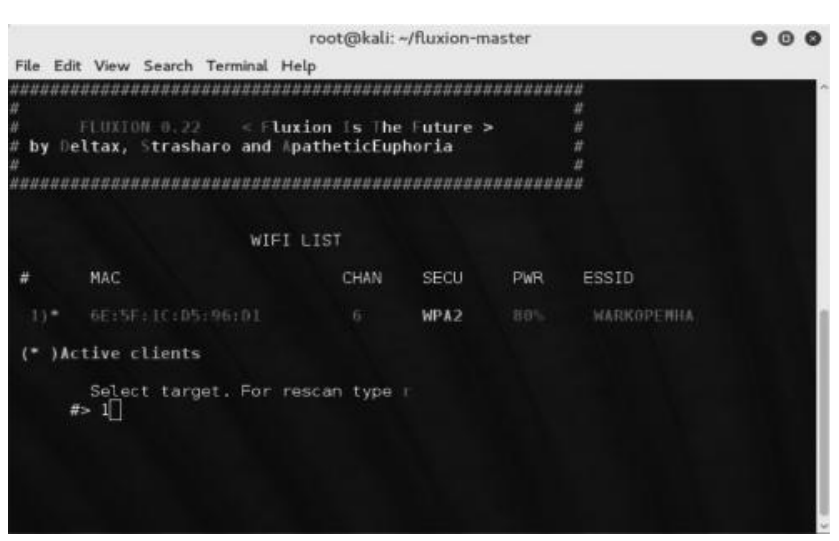

Gambar 7. Daftar jaringan WiFi 


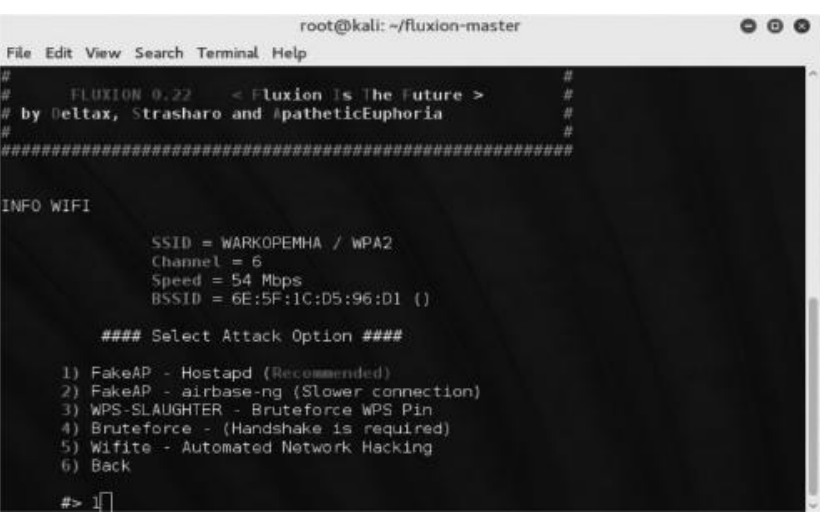

Gambar 8. Jenis-jenis penyerangan

3. Melakukan konfigurasi tool-tool yang telah tersedia pada Kali Linux ataupun tool tambahan lainnya agar proses penyerangan terhadap client dapat berjalan dengan baik.

4. Menunggu user yang terkoneksi ke internet untuk mendapatkan handshake ataupun informasi mengenai SSID, MAC address, IP address, Channel dan lain-lain. Sehingga diperoleh sebuah paket berupa kode enkripsi untuk dipecahkan menjadi password WPA2PSK.

5. User attack dapat mengakses jaringan WiFi dengan memanfaatkan handshake dan paket kode enkripsi yang telah dipecahkan dengan menggunakan tool-tool pada Kali Linux, jika handshake sulit untuk didapatkan dari user itu dikarenakan jaringan user lama dalam merespon paket yang dikirim dari user attack ataupun frame nya yang rendah, sehingga harus mengulangi lagi penggunaan tool kepada user yang lain.

6. Hasil cracking, menampilkan password

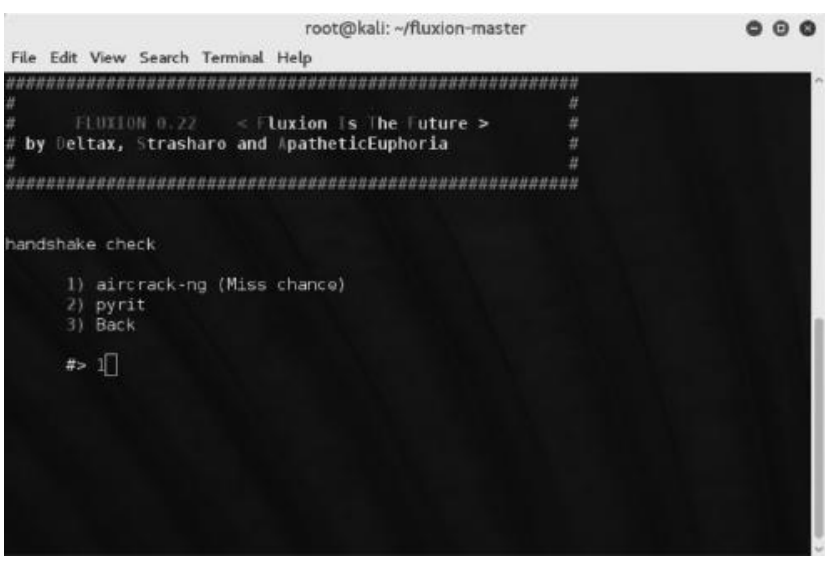

Gambar 9. Pengecekan handshake

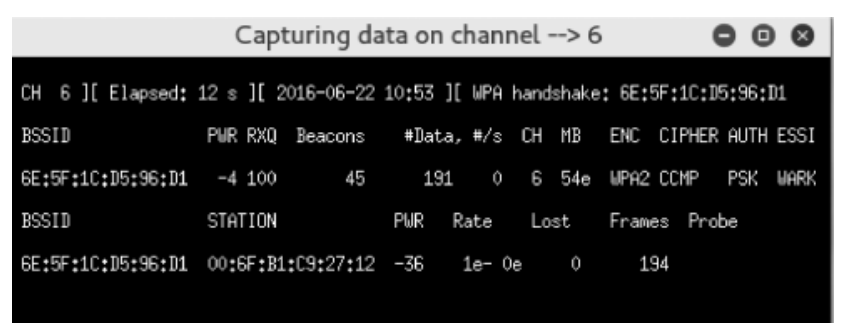

Gambar 10. Handshake yang telah diperoleh dari channel target.

WPA2-PSK dari proses penyerangan terhadap user dengan memecahkan kode enkripsi yang telah di dapat dari user.

7. Menarik kesimpulan, untuk memutuskan sebuah kesimpulan yang bisa kita terapkan pada saat proses penyerangan oleh user attack terhadap keamanan WPA2-PSK pada jaringan WiFi dilihat dari sisi (success/fail).

8. Menulis laporan dari proses-proses penyerangan yang telah dilakukan untuk mendapatkan password keamanan WPAPSK pada jaringan WiFi.

\section{Tahapan Untuk Mengetahui Password}

Pada pengujian ini, User Attack melakukan penetrasi terhadap user dengan cara mencari IP Address user yang terkoneksi pada jaringan WiFi menggunakan tool Fluxion yang telah di install di Kali Linux, Lalu User Attack Menginjeksi paket dengan melakukan Deauthentication Attack, sehingga data yang dibutuhkan yaitu enkripsi key dan handshake data dapat diambil dengan cepat dan mengurangi waktu yang dibutuhkan untuk melakukan cracking, setelah di dapatkan data handshake, User Attack melakukan cracking WPA2 dengan menggunakan Fluxion untuk mengetahui Password WPA2-PSK melalui user yang terhubung ke jaringan WiFi. Dalam melakukan Password Attack, User Attack hanya membutuhkan user yang terkoneksi ke jaringan WiFi tersebut.

\section{Hasil Dan Pembahasan}

Berdasarkan rancangan sistem yang telah dijelaskan sebelumnya maka dihasilkan suatu pengujian terhadap keamanan WPA2-PSK pada jaringan WiFi yaitu dengan menggunakan tahapan untuk mengetahui password melalui pemanfaatan user. 


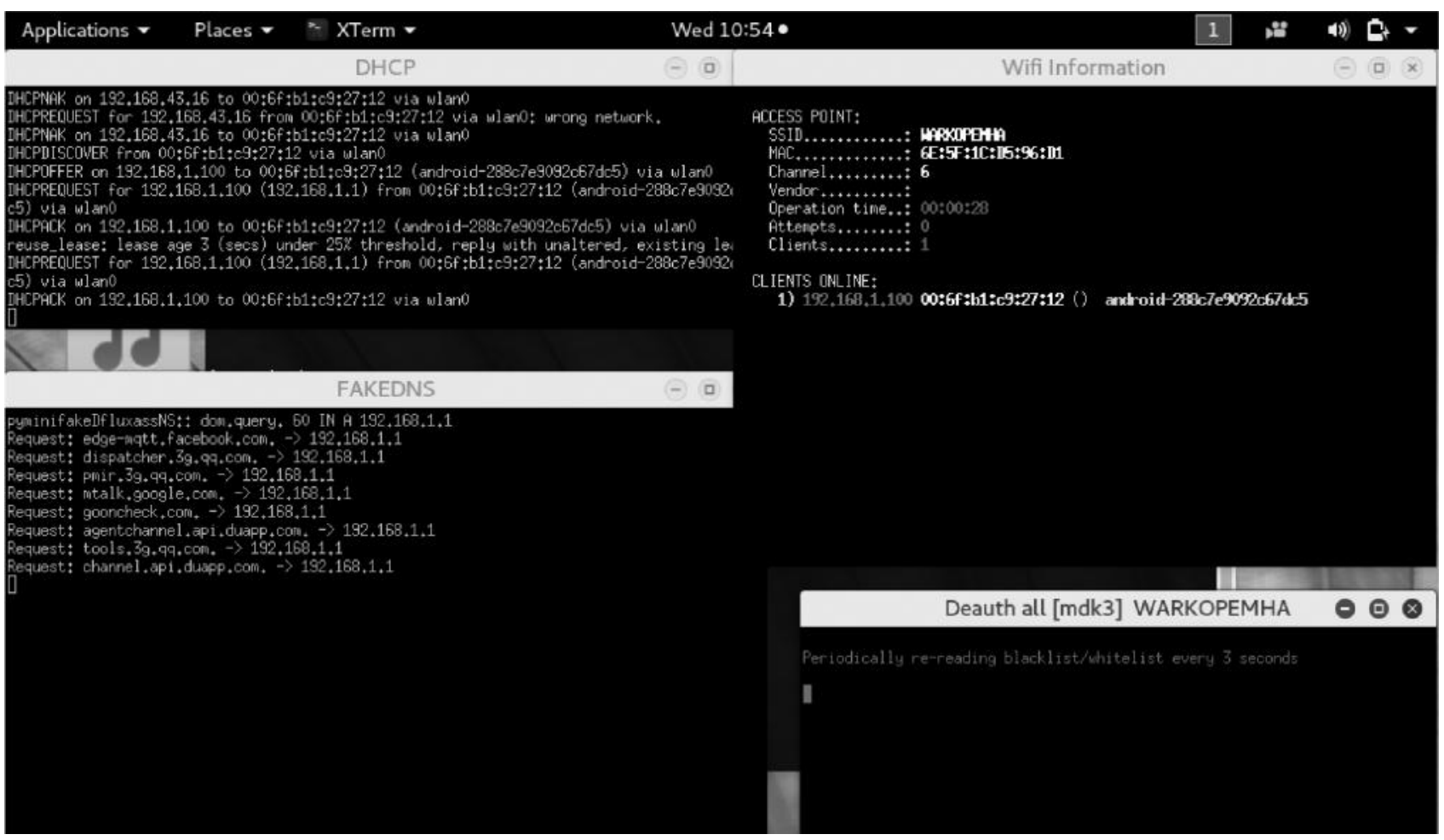

Gambar 11. Aktivitas mendapatkan password dengan memanfaatkan user

Tahapan Untuk Mengetahui Password Melalui Pemanfaatan User

Pada tahapan untuk mengetahui password ini, user attack dapat memanfaatkan tool Fluxion yang bisa di download melalui website https:// github.com/deltaxflux/fluxion/ kemudian setelah di download dan melakukan extract di desktop, jalankan tool tersebut dengan mengetikkan perintah sebagai berikut.

$$
\begin{aligned}
& \text { "1s" } \\
& \text { "cd fluxion-master" } \\
& \text { "./fluxion" }
\end{aligned}
$$

Setelah mengetikkan perintah di atas pada jendela terminal Kali Linux maka tampilan tool fluxion ketika dijalankan dapat dilihat pada gambar 5 berikut ini.

Selanjutnya pada proses ini user attack dapat memilih nomor satu untuk melanjutkan penyerangan yang akan ditampilkan pada Gambar 6.

Tahap selanjutnya user attack dapat memilih salah satu pilihan misalnya nomor satu yaitu all channel sehingga proses selanjutnya akan ditampilkan pada Gambar 7 berikut ini.

Berdasarkan Gambar 7 dihasilkan informasi mengenai jaringan WiFi dan user dengan BSSID
"63:5F:1C:D5:96:D1" yang merupakan alamat MAC address dari salah satu nama jaringan $\mathrm{WiFi}$, lalu PWR merupakan Power Level yaitu kekuatan daya pancaran sinyal yang mempunyai daya pancaran sinyal "-24 dBm" dengan nilai minus agar mendapatkan daya pancar minimum untuk memperoleh throughput 54 Mbps. Maka langkah selanjutnya ialah memilih jaringan target seperti pada Gambar 8.

Berdasarkan Gambar 8 dihasilkan bahwa MAC address “63:5F:1C:D5:96:D1" ialah

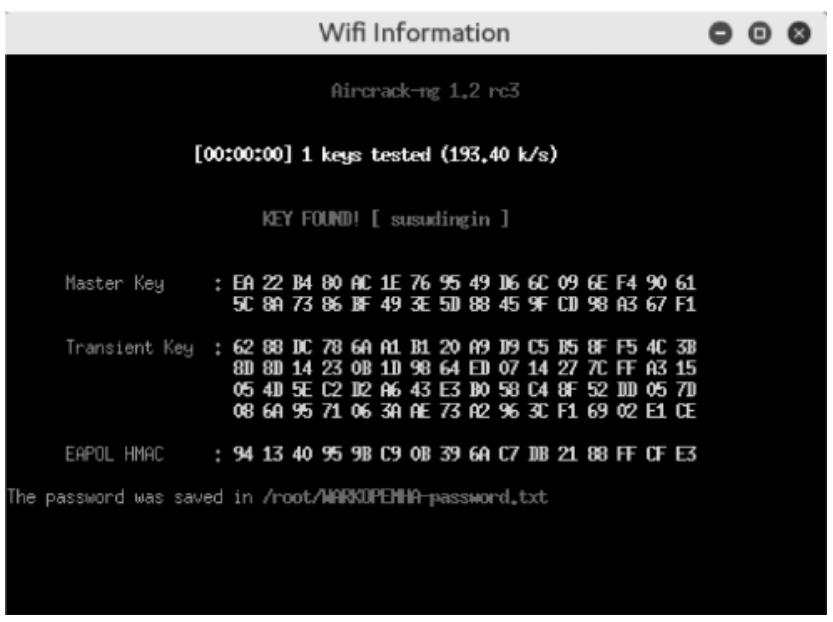

Gambar 12. Hasil password pada aircrack-ng 
MAC address jaringan target yang akan dipilih untuk melakukan penyerangan oleh user attack, sedangkan channel "6" ialah jaringan target yang berada pada frekuensi $2.4 \mathrm{GHz}$, lalu security "WPA2" ialah jenis keamanan dai jaringan tersebut. Maka langkah selanjutnya ialah memilih jenis penyerangan seperti pada Gambar 9.

Setelah memilih jaringan target yang akan digunakan untuk proses penyerangan, maka akan ditampilkan macam-macam jenis penyerangan, kita dapat memilih salah satu dari penyerangan tersebut misalnya nomor satu "FakeAP - Hostapd", sehingga akan ditampilkan proses pengecekan paket handshake seperti pada Gambar 10 berikut ini.

Berdasarkan Gambar 10 dapat dilihat pilihan pengecekan handshake di antaranya "aircrackng" dan "pyrit" yang berfungsi untuk pengecekan handshake, dari beberapa pilihan pada tersebut misalnya kita dapat memilih nomor satu yaitu "aircrack-ng", sehingga akan ditampilkan proses bagaimana memperoleh handshake yang dibutuhkan oleh user attack tersebut pada gambar 11 berikut ini.

Berdasarkan Gambar 11 dihasilkan bahwa "WPA handshake" telah diperoleh pada jam 10:53 dalam waktu " 12 seconds" pada channel "6" yang merupakan request user attack dari user "63:5F:1C:D5:96:D1" yang terhubung kepada jaringan WiFi.

Ketika request paket handshake terjadi seluruh user yang terkoneksi terhadap jaringan tersebut akan terputus dan ketika user mengoneksikannya kembali maka handshake tersebut telah didapatkan oleh user attack. Kemudian akan ditampilkan jendela informasi mengenai user yang telah terkoneksi kembali dengan password yang benar. Lalu handshake yang masih terenkripsi tersebut dilakukan pengecekan oleh aircrack-ng hingga diperoleh password jaringan WiFi dengan memanfaatkan user seperti pada Gambar 12 berikut ini.

Setelah menunggu beberapa waktu hingga terkoneksi kembali, maka password tersebut akan muncul dari proses pengecekan handshake oleh "aircrack-ng" seperti pada Gambar 13 berikut ini.

Berdasarkan Gambar 13 dihasilkan bahwa password telah berhasil didapatkan oleh aircrack$n g$ yaitu "susudingin" dengan master key yang terdiri dari 64 bit, transient key 128 bit, dan EAPOL HMAC 32 bit, untuk EAPOL HMAC di konversikan dari bit ke bilangan desimal sehingga diperoleh password "susudingin". Password tersebut telah disimpan pada folder / root/warkopemha-password.txt.

\section{Kesimpulan Dan Saran}

Berdasarkan hasil penelitian ini, maka dapat disimpulkan bahwa untuk mengetahui password WPA2-PSK penyerang memerlukan user yang terkoneksi ke jaringan WiFi dengan menggunakan tool Fluxion. Pada pengujian SSID palsu melalui user, penyerang membuat sebuah SSID lain yang hampir sama dengan SSID asli, namun yang membedakannya ialah SSID asli memiliki pengamanan WPA2-PSK sedangkan SSID palsu bersifat open. Jadi, user yang tidak teliti dalam menggunakan koneksi jaringan akan terhubung ke SSID palsu, penyerang akan mudah mendapatkan password karena user memasukkan password seperti SSID asli ke dalam sebuah halaman khusus yang telah dibuat oleh tool WiFiPhisher. Dalam tahapan mengetahui password penyerang masih membutuhkan user yang terhubung ke jaringan WiFi, bukan melakukan proses mendapatkan password secara individu.

\section{Daftar Pustaka}

Heather, D. Lane. 2009. Security Vulnerabilities and Wireless LAN Technology. Virginia Beach : SANS Institute.

Prabowo W. Onno. 2008. Belajar Menjadi hacker. Buku Pintar : Jakarta.

Priyambodo, Tri Kuntoro. 2008. Jaringan WiFi. Graha Ilmu : Yogyakarta.

Satria, Lucky. 2014. Pengertian IP Spoofing, Cara Kerja dan Pencegahan IP Spoofing. Informatika : Bandung.

Sinambela, Josua. 2007. Jaringan Wireless dan Keamanan Wireless. Jurnal Keamanan Jaringan Komputer DINAMIK Volume X.

Supriyanto, Aji. 2007. Analisis Kelemahan Keamanan Pada Jaringan Wireless. Jurnal Teknologi Informasi DINAMIK Volume XI. Suryani, Izny. 2013. Contoh-contoh Kasus Cybercrime. Informatika : Bandung. Wirdasari, Dian. 2008. Prinsip Kerja Kriptografi dalam Mengamankan Informasi. Jurnal SAINTIKOM Vol.5 No.2. 